\title{
An Overview of Obesity and Bariatric Surgery: a Community-Based Study in Buraydah City, Saudi Arabia
}

\author{
Dr. Saleh Al Mesned, Dr. Abdulrahman Al Mesned, Dr. Majeda Farajat
}

\begin{abstract}
Background. Saudi Arabia (SA) has been widely involved in the epidemic of obesity. In 2016, World statistics showed that SA was highly ranked in obesity with a prevalence of around $34 \%$. Management of obesity can include lifestyle changes, medications, or Bariatric Surgery (BS). BS has been shown to be effective intervention for weight loss, diabetes management, Dyslipidemia, and reducing mortality risk. Accordingly, this study aimed to assess knowledge and awareness of Buraydah Community about obesity with regards to causes and management including BS.

Methods. This cross-sectional survey targeted the general population in Buraydah City, Saudi Arabia from June to July 2018. The survey covered multiple public places in Buraydah using a convenience sample $(n=516)$. Data were collected using two tools; self-administered questionnaires and Anthropometric measurements of weight and height. The questionnaire encompassed a set of socio-demographic variables, awareness of obesity's causes and prevention and awareness of BS as a management for obesity. Data was analyzed using descriptive statistics and Chi-Square test.
\end{abstract}

Results. Around one fourth of the sample $(24.4 \%)$ were classified to be obese, the vast majority of participants $(90.5 \%)$ were unaware of their own BMI classification. Furthermore, participants generally had a good general knowledge about obesity, most of them believed that lack of physical activity was the most common cause of obesity and that engaging in sport activities is the best management of obesity. The majority of the sampled community members $(\mathbf{7 8 . 3 \%})$ had a good knowledge about BS, whereas $21.7 \%$ of them showed positive attitude toward BS. Furthermore, Social media was the most common source of information about BS. Significant differences in knowledge about BS were limited to gender, while significant differences in attitude included age group, marital status, educational level, and classification of BMI and knowledge of self-BMI.

Conclusion. Although the prevalence of obesity in Buraydah City is a little less than other regions of SA, a local strategy to compact this epidemic is needed. The option of BS for eligible cases of obesity should be addressed. Accordingly, efforts needed to educate the public about BS, which is an ultimate solution for obesity.

Index Terms - Obesity, Community, Knowledge, Attitude, Bariatric Surgery.

Dr. Saleh Al Mesned. Medical Intern, Qassim/KSA.

Dr. Abdulrahman Mesned. Pediatric Cardiology Department- Prince Sultan Cardiac Center-Qassim/KSA

Dr. Majeda Farajat, Quality Management and Patient Safety Department-Prince Sultan Cardiac Center-Qassim/KSA..

\section{INTRODUCTION}

Highlight Obesity has been a major epidemic in the $21^{\text {st }}$ century worldwide [1]. It is now evident that obesity is a risk factor for multiple health conditions. Numerous cardiovascular diseases have been linked with obesity including coronary heart disease, angina, myocardial infarction, atrial fibrillation, heart failure and sudden cardiac death [2,3]. Obesity is also an identified risk in type 2 diabetes [4]. Furthermore, obesity also plays a role in the development and severity of multiple respiratory problems such as obstructive sleep apneas, asthma, chronic obstructive pulmonary disease, and pulmonary embolism, have been linked to obesity [5,6]. Moreover, obesity is a risk factor for both vitamin $\mathrm{D}$ deficiency and bone health in aging individuals $[7,8]$.

Saudi Arabia (SA) has been widely involved in the epidemic of obesity. In 2016, World statistics showed that SA was highly ranked in obesity epidemic compared with worlds countries (world 15th most obese country), where obesity prevalence was estimated be around 34\% [9]. In accordance, a local community-based study, which encompassed 20,000 participants from all regions of SA, reported that the overall prevalence of obesity was around $36 \%$ [10].

Given the role of obesity in the etiology of chronic diseases, Saudi Arabia is expected to face a big challenge due to the burden of chronic diseases in spite of its rich resources [11]. Accordingly, a good management of obesity is required Management of obesity can include lifestyle changes, medications, or Bariatric Surgery (BS), also known as metabolic surgery. BS has been shown to be effective intervention for weight loss, diabetes management, Dyslipidemia, and reducing mortality risk [12-14]. There is a lack of community beliefs and knowledge about Bariatric surgery and other weight loss interventions and lifestyle modifications. Bariatric surgery is still a relatively safe intervention.

This study aimed to assess knowledge and awareness of Buraydah Community about obesity with regards to causes and management including Bariatric Surgery (BS). Accordingly, this study had the following objectives:

1- To describe the prevalence of obesity among Buraydah Community.

2- To assess the awareness of participants' own BMI classification and self-rated weight

3- To assess the general knowledge of Buraydah 
Community about Obesity.

4- $\quad$ To assess the awareness of Buraydah Community regarding the causes of Obesity.

5- To describe the community opinion about the recommended methods for 35-year-old obese woman to lose weight.

6- To assess community knowledge and attitude on Bariatric Surgery.

7- To identify the sources of information regarding BS among the community.

8- To identify the reasons for not recommending BS, if any.

9- To describe the relationship between knowledge and attitude among the socio-demographic characteristics of participants.

\section{MethodOLOGY}

\section{Procedure}

This cross-sectional survey targeted the general population in Buraydah City, Saudi Arabia from June to July 2018. The survey covered multiple public places in Buraydah using a convenience sample $(n=516)$, namely Al Nakeel mall, Othaim mall, Dates city, King Khalid Cultural Center, King Abdullah National park, Bene coffee shop, Dunkin Donuts, Arabic Star coffee shop and Gunes Café.

Data were collected using two tools; self-administered questionnaires and Anthropometric measurements of weight and height.

The questionnaire was administered to a small group of people $(n=15)$ to get feedback on the questions (e.g., clarity of words, understandability of the questions) and on the questionnaire itself (e.g., time needed to complete the questionnaire). An introductory statement was provided to explain the purpose of the study and ensure the anonymity and privacy of the respondents and that participation was voluntary. Furthermore, respondents were informed that their submission of the filled questionnaire presents passive informed consent. Ethical approval was obtained from Qassim Region Research Ethics Committee .

\section{Measures}

\section{A. Questionnaire}

The questionnaire encompassed the following measures: Demographic \& Background characteristics: The following demographic and background characteristics were included:

- Age. Respondent's age was categorized into four categories $(18-25$ years $=1 ; 26-35$ years $=2$; $36-45$ years $=3 ;>45$ years old $=4$ ).

- Gender. Respondents were asked to specify their gender (male $=1$, female $=2$ ).

- Marital Status. Respondent's Marital Status was dichotomized as either married $(=1)$ or unmarried $(=2)$.

- Educational Level. Respondent's Educational Level was dichotomized as either High school or below $(=1)$ or Diploma/Bachelor or above $(=2)$.

\begin{abstract}
- Knowledge and attitude towards BS
- Knowledge. Respondents' Knowledge about BS was assessed using response to a set of five (5) questions rated on a weighted 3-point scale $(\mathrm{No}=1$; Unsure $=2 ; \mathrm{Yes}=3)$. A deeper analysis at item level was performed first. Afterwards, the overall knowledge scores were calculated such that a higher score indicates a better knowledge.

- Attitude. Respondents' attitude towards BS was assessed using a response to one question rated on a weighted 3- point scale $(\mathrm{No}=1$; Unsure $=2$; Yes=3).
\end{abstract}

B. Anthropometric Measurements

Participants' height (in meters) and weight (in kg.) were measured. Body Mass Index (BMI) was calculated according to this formula: $\left(\mathrm{BMI}=\mathrm{Weight} / \mathrm{Height}^{2}\right)$. Overweight \& obesity were determined according to WHO BMI reference [15].

\section{Statistical Analysis}

Collected date was coded and entered into an excel spreadsheet for initial editing, then exported to SPSS for statistical analysis (version 20). Both descriptive and inferential statistics had been performed where numbers and percentages were used to present all categorical variables and mean \pm standard deviation were used to summarize all continuous variables. A p-value cut off point of 0.05 at $95 \%$ CI was used to determine statistical significance. The relationships between socio-demographic and the dependent variables were assessed using by chi square test.

\section{RESULTS}

\section{Characteristics of the Sample}

The total number of participants was 516. As shown in table 1 , around half of the sample $(49.2 \%)$ aged between $18-25$ years and only $7.0 \%$ aged more than 45 . Furthermore, the sample consisted of $54.1 \%$ females. With respect to Marital Status, more than half $(59.3 \%)$ of the respondents were unmarried. Additionally, the majority of the participants $(70.0 \%)$ had an educational level of diploma or higher.

\section{BMI Related Variables}

As shown in table 2, the mean weight of the participants was $72.4 \mathrm{Kg}(\mathrm{SD}=20.1)$ and the mean height was $163.9 \mathrm{~cm}$ ( $\mathrm{SD}=9.6)$. With regards to the classification of participants according to their BMI, around $40 \%$ ranked normal, while around $29 \%$ and $24 \%$ were ranked overweighed and obese, respectively. Moreover, $7 \%$ of participants were ranked underweighted. 
Table 1. Socio-demographic characteristics of the sample population $(\mathrm{n}=516)$.

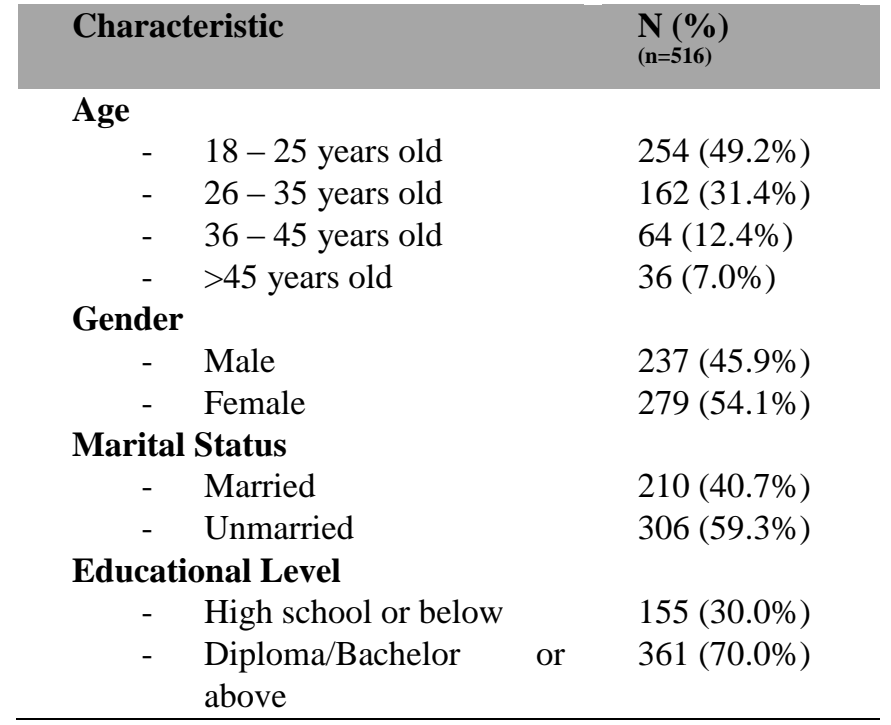

Table 2. BMI related variables $(\mathrm{n}=516)$.

\begin{tabular}{|c|c|c|}
\hline \multicolumn{2}{|c|}{ Variable } & $\begin{array}{l}\mathbf{N}(\%) \\
(\mathrm{n}=516)\end{array}$ \\
\hline \multirow{2}{*}{\multicolumn{2}{|c|}{$\begin{array}{l}\text { Weight in } \mathrm{Kg}(\text { mean } \pm \text { SD }) \\
\text { Height in } \mathrm{Cm}(\text { mean } \pm \text { SD })\end{array}$}} & $72.4 \pm 20.1$ \\
\hline & & $\begin{array}{ll}163.9 \quad \pm \\
09.6\end{array}$ \\
\hline \multicolumn{3}{|c|}{ BMI Categories } \\
\hline \multicolumn{2}{|c|}{ - Normal } & $\begin{array}{c}36(7.0 \%) \\
204 \\
(39.5 \%)\end{array}$ \\
\hline \multicolumn{2}{|c|}{ - Overweight } & $\begin{array}{c}150 \\
(29.1 \%)\end{array}$ \\
\hline \multicolumn{2}{|c|}{ - $\quad$ Obese } & $\begin{array}{c}126 \\
(24.4 \%)\end{array}$ \\
\hline \multicolumn{3}{|c|}{$\begin{array}{l}\text { Awareness of participants' } \\
\text { own BMI Classification }\end{array}$} \\
\hline- & $\begin{array}{l}\text { Aware } \\
\text { Unaware }\end{array}$ & $\begin{array}{c}49(9.5 \%) \\
467 \\
(90.5 \%)\end{array}$ \\
\hline \multicolumn{3}{|c|}{ Self-Rated Weight } \\
\hline - & Normal & $\begin{array}{c}218 \\
(42.2 \%)\end{array}$ \\
\hline- & Overweight & $\begin{array}{c}202 \\
(39.1 \%)\end{array}$ \\
\hline- & Obese & $60(11.6 \%)$ \\
\hline- & I don't know & $36(7.0 \%)$ \\
\hline
\end{tabular}

With regards to the awareness of participants' about their own BMI classification, results showed that the vast majority of the participants $(90.5 \%)$ were unaware of it. On the other hand, $42.2 \%, 39.1 \%$ and $11.6 \%$ of participants rated themselves normal, overweight, obese respectively.

When asked about the classification of their weight, $42.2 \%$ stated that their weight was normal, 39.1\% thought they were overweight, $11.6 \%$ thought they were obese while $7 \%$ of them had no idea about their actual weight.

\section{General knowledge about Obesity.}

Most participants agreed regarding statements about obesity to which we identified as follows; "Is obesity a disease?", "Obesity is an increasing fat?", "Abnormal lifestyle may lead to obesity?", "Sports activity reduces the likelihood of obesity?" and "Is there a relationship between obesity and incidence of DM?" with the exception of "Is there a need for surgical intervention to treat obesity where negative response was slightly higher $(52.3 \%)$ compared to positive $(31.6 \%)$ (Figure 1).

\section{Awareness of the Causes of Obesity.}

Figure 2 shows the causes of obesity from participants' perspective. Based on the results, lack of physical activity was the most common cause of obesity $(61.6 \%)$, followed by excessive food intake $(42.2 \%)$, next was medical complication $(10.9 \%)$ and hereditary $(5 \%)$ with $16.7 \%$ for mixed reasons.

Community opinion about the recommended methods for 35-year-old obese woman to lose weight.

Figure 3 presents the respondents' recommendations for a 35-year-old obese woman trying to lose weight. The most frequently reported recommendation(73.4\%), was "to engage in sport activities" and the least recommended (5\%) was "to undergo medication to achieve ideal weight"

\section{Community Knowledge and Attitude on Bariatric Surgery.}

Table 3 presents the knowledge and attitude toward the effectiveness of BS. $96.7 \%$ of the respondents were having enough knowledge about BS to treat obesity and $90.7 \%$ of them believe that BS helps to lose weight. 


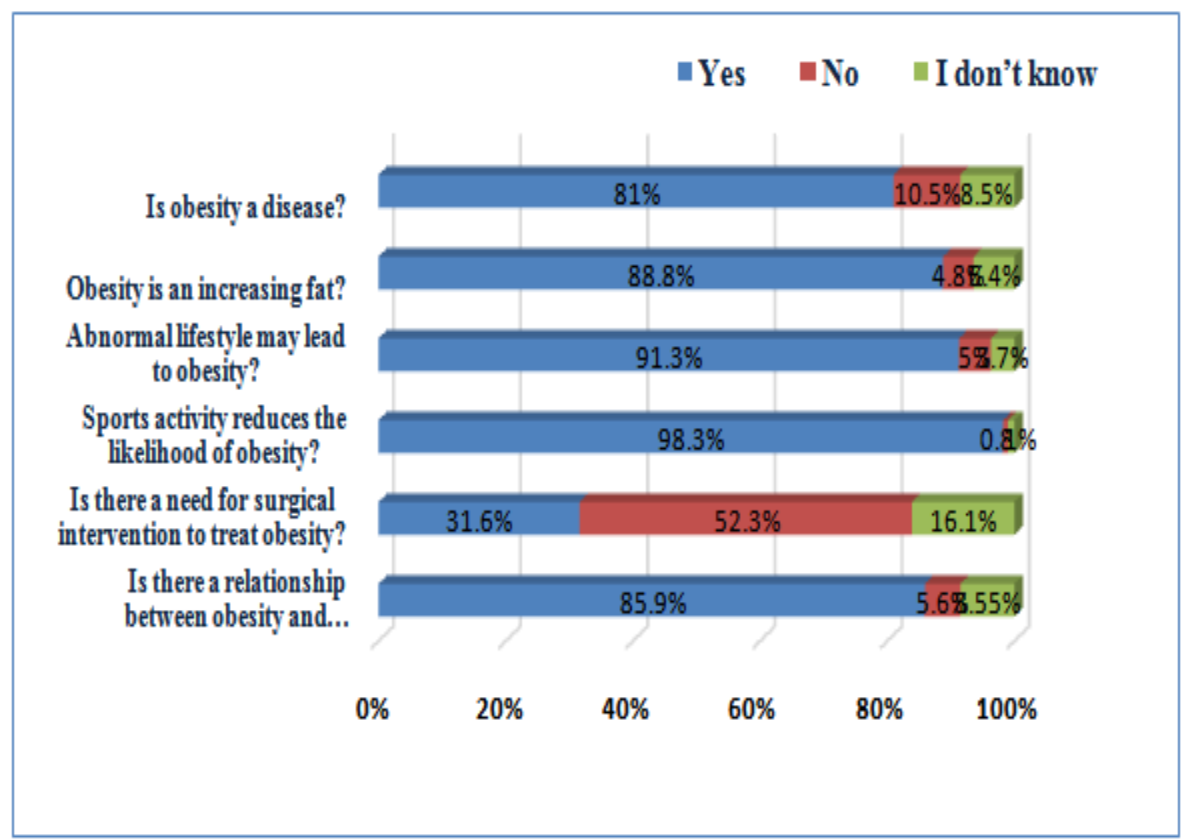

Figure 1: General knowledge about obesity.

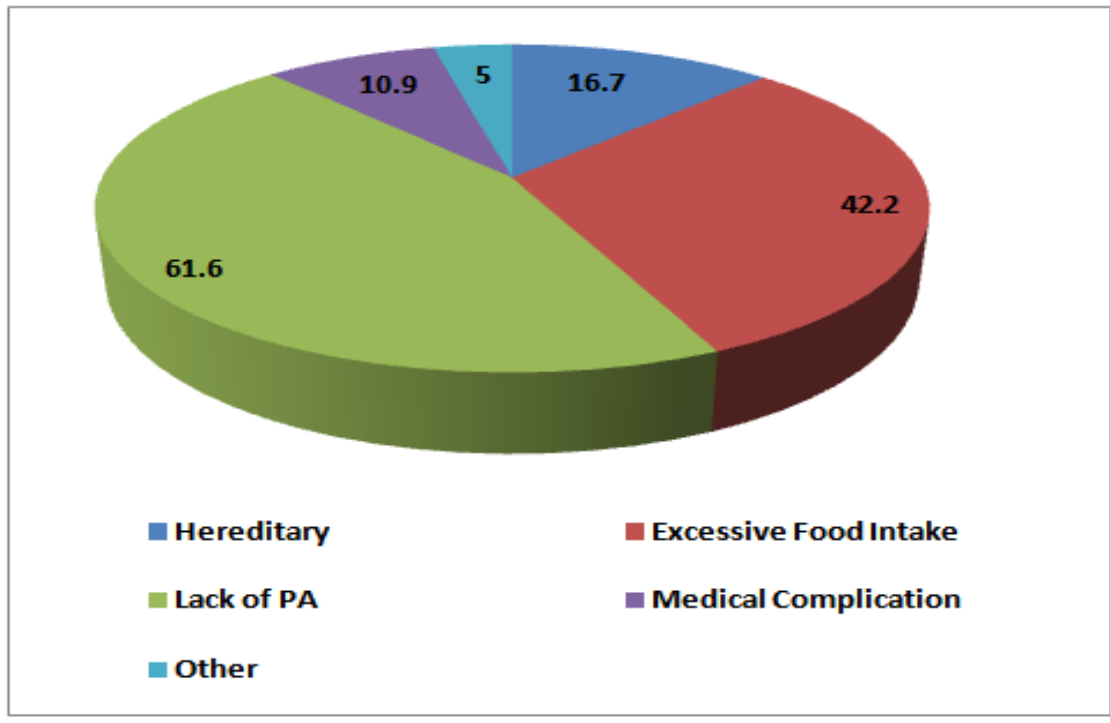

Figure 2: Awareness of the Causes of Obesity.

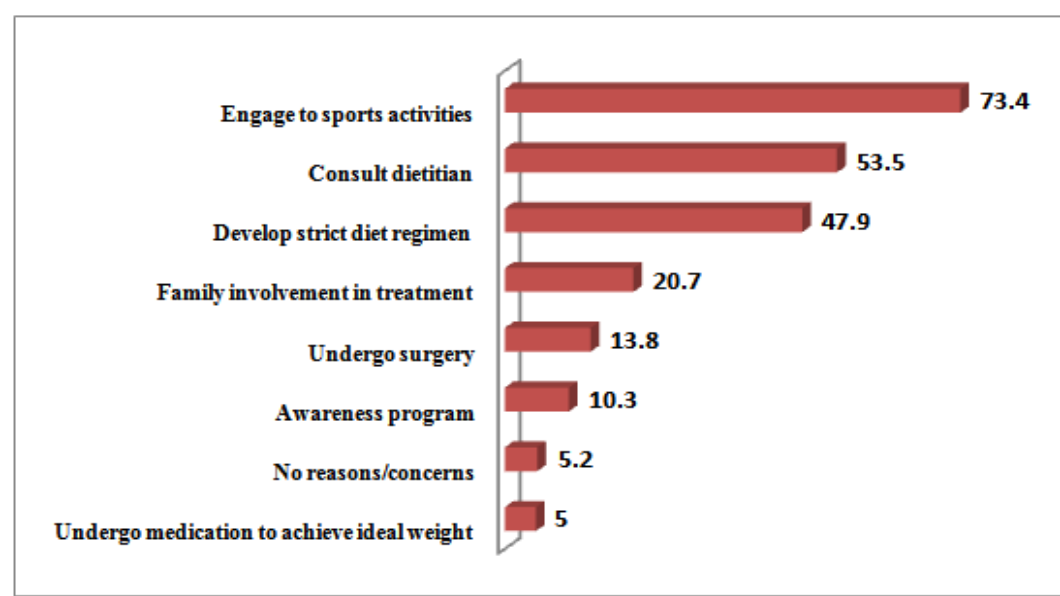

Figure 3. Community's opinion about the recommended methods for a 35-year-old obese woman to lose weight. 
Table 3. Community knowledge \& attitude towards the effectiveness of BS ( $n=516)$.

\begin{tabular}{|l|c|c|c|}
\hline \multicolumn{1}{|c|}{ Statement } & Yes & No & Uncertain \\
\hline K1. Have you heard about a surgery to treat obesity? & $\begin{array}{c}499 \\
(96.7 \%)^{\dagger}\end{array}$ & $17(03.3 \%)$ & 0 \\
\hline K2. Does the surgery help to lose weight? & $\begin{array}{c}468 \\
(90.7 \%)^{\dagger}\end{array}$ & $12(02.3 \%)$ & $36(07.0 \%)$ \\
\hline $\begin{array}{l}\text { K3. We do not need surgical intervention to treat } \\
\text { obesity? }\end{array}$ & $\begin{array}{c}222 \\
(43.0 \%)\end{array}$ & $\begin{array}{c}176 \\
(34.1 \%)\end{array}$ & $\begin{array}{c}118 \\
(22.9 \%)^{\dagger}\end{array}$ \\
\hline K4. Complications might occur after the operation & $\begin{array}{c}300 \\
(58.1 \%)\end{array}$ & $60(11.6 \%)$ & $\begin{array}{c}156 \\
(30.2 \%)\end{array}$ \\
\hline K5. Can the bariatric operation lead to death? & $\begin{array}{c}195 \\
(37.8 \%)\end{array}$ & $\begin{array}{c}125 \\
(24.2 \%)\end{array}$ & $\begin{array}{c}196 \\
(38.0 \%)^{\dagger}\end{array}$ \\
\hline \multicolumn{2}{|l}{ A1. Would you recommend Bariatric Surgery? } & $\begin{array}{c}142 \\
(27.5 \%)\end{array}$ & $\begin{array}{c}374 \\
(72.5 \%)\end{array}$ \\
\hline
\end{tabular}

${ }^{\dagger}$ Signifies the most appropriate answer. K - Knowledge; A - Attitude.

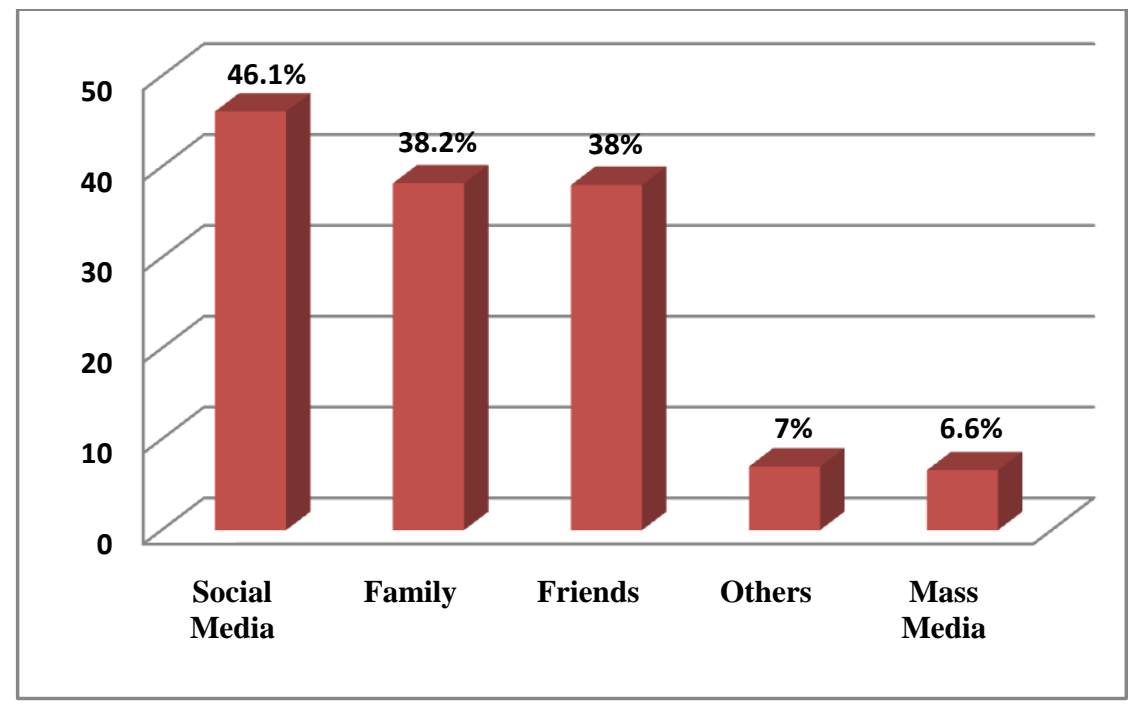

Figure 4. Sources of information regarding BS.

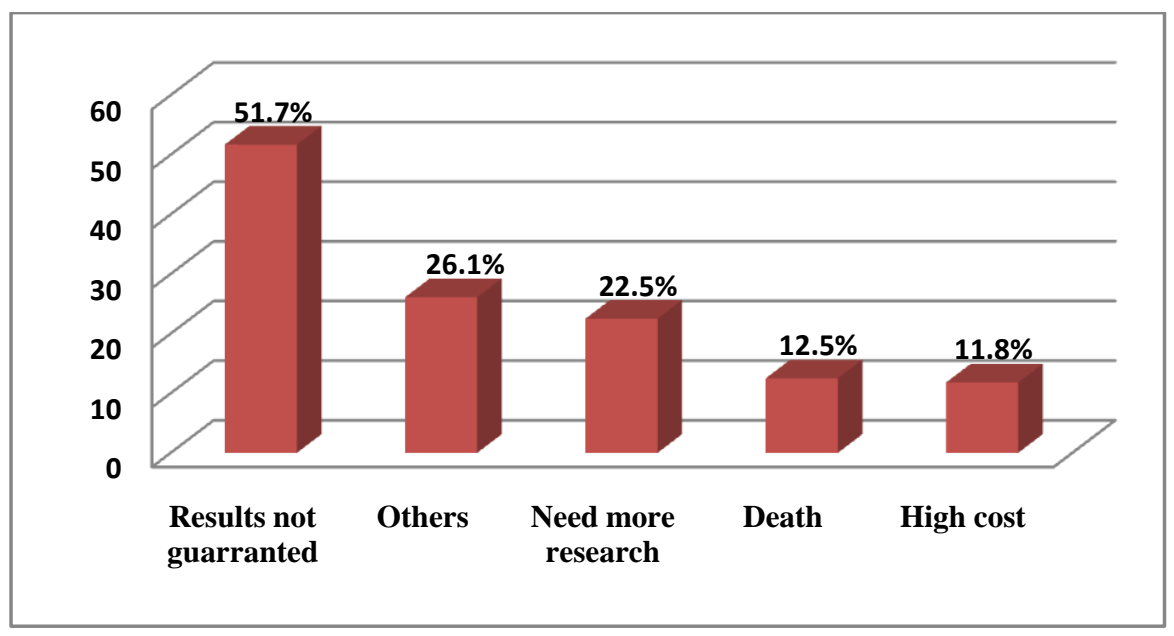

Figure 5. Reasons for not recommending BS. 
Less than a half of the participants thought that surgical intervention was unnecessary to treat obesity while $58.1 \%$ believe that complication might occur after BS and $37.8 \%$ believe that BS can lead to death. There were $27.5 \%$ of them would recommend BS to other person.

\section{Sources of Information regarding BS.}

As shown in figure 4 , the sources of information regarding BS revealed, Social media $(46.1 \%)$, followed by family $(38.2 \%)$, friends $(38 \%)$, mass media $(6.6 \%)$ and others entity (7\%).

\section{Reasons for not recommending BS, if any.}

Based on participants rating, the reasons for not recommending BS were as follows; results not guaranteed $(51.7 \%)$, followed by the need of more research and experimentation $(22.5 \%)$, next cause of mortality $(12.5 \%)$ and high cost $(11.8 \%)$ with other mixed reasons $(26.1 \%)$ (Figure 5).

Relationship between knowledge and attitude among the socio-demographic characteristics of participants.

We used chi square test (table 4) to measure the relationship between knowledge and attitude among the socio-demographic characteristics of participants with p-values which indicates whether the relationship is statistically significant where $p \leq 0.05$ has been accepted as the significant level for all statistical tests. Based on the results, age group in years was statistically significant at attitude (p-0.019) contrary to knowledge with negative relationship. Significant relationship found on gender and knowledge (p-0.007) while attitude was no relationship. Significant relationship was also found on marital status and attitude (p-0.004) as opposed to knowledge without having any relationship. Educational level found to be statistically significant associated with attitude (p-0.022) while knowledge was not. There was significant relationship found on attitude and the classification of BMI (p-0.001) however, knowledge deemed negatively associated. Knowledge of self-BMI also found to be statistically significant with attitude $(\mathrm{p}-<0.001)$ while knowledge found to have no relationship.

\section{DISCUSSION}

Obesity is one of the significant factors why overweight patients undergo BS. Regardless of any complications and the high cost, BS is still deemed to be the most effective method to lose weight. In our study, we aimed to assess the general knowledge and attitude of the community regarding the effectiveness of BS. The overall prevalence of good knowledge in this study revealed 404 accounted for $78.3 \%$ of respondents and 112 accounted for $21.7 \%$ were classified as poor knowledge. With regards to attitude, there were 374 yielding an overall percentage of $72.5 \%$ classified as negative attitude while 142 with $27.5 \%$ were being identified as positive attitude. We observed that this is the first paper in Saudi Arabia that elaborated the overall knowledge and attitude of the public regarding the effectiveness of BS. An article published in the United States [16] to evaluate the "attitudes about the safety and efficacy of BS among patients with type 2 diabetes and a Body Mass Index of 30-40, reported that the overall positive attitude of the patients regarding BS was $20.3 \%$. This finding is comparable to our study result. The prevalence of knowledge and attitude towards the effectiveness of BS has been rarely discussed globally so further research is needed in order to validate the findings of this study.

Moreover, respondents in this study had enough knowledge about BS to treat obesity and they believe that BS helps to lose weight. Less than a half of them thought that surgical intervention was unnecessary to treat obesity while majority believe that complications might occur after BS and minority of the participants believe that BS can lead to death. There were one third of respondents who would recommend BS to other persons. Alqurashi et al published an article about "assessment of knowledge and attitude and practice of safety, effectiveness and consequences of BS among community in Saudi Arabia [13]. Among the general public they surveyed, most of them had shown good knowledge about obesity but low favorable beliefs about BS. They further reported that more respondents had bad knowledge about the importance of surgery for getting rid of obesity and most of them knew that surgery decreases the body weight and that it might result with some complications and mortality. These findings were in congruent to our study results. Although some points might be conclusive otherwise both our papers indicated about the danger of complication after operation. The effectiveness of BS had been discussed also in an article published by Sikorski and colleagues [17]. They reported that about half of their subjects agreed that weight loss surgery (WLS) was "very effective" while still a quarter of them did not ascribe effectiveness to WLS. On the other hand, majority of the respondents in their study would not recommend WLS. These study findings were consistent to our outcome which further validated the substantiality of the results in this paper.

This paper also measures the relationship between knowledge and attitude among the socio-demographic characteristics of the participants. Based on the results, age group in years was a significant factor of attitude contrary to knowledge with negative relationship. Significant relationships found on gender and knowledge while attitude revealed no relationship. Significant relationships were also found on attitudes against the following socio-demographic variables such as: marital status, educational level, classification of BMI and knowledge of self-BMI however all of them deemed to be negative against knowledge. Since limited paper had been published in the same context, we deemed that this is the first paper to present the correlation between knowledge and attitude versus the socio-demographic characteristics of participants here in Saudi Arabia.

In conclusion, although the prevalence of obesity in Buraydah City is a little less than other regions of SA, a local strategy to compact this epidemic is needed. The option of BS for eligible cases of obesity should be addressed. Accordingly, efforts needed to educate the public about BS, which is an ultimate solution for obesity. Although the general knowledge of public about BS was deemed good, still most of them held negative attitude towards it. In this regard, continuous awareness among the general population is needed. 
Table 4. Relationship between knowledge and attitude among the socio-demographic characteristics of participants $(n=516)$.

\begin{tabular}{|c|c|c|c|c|}
\hline \multirow[b]{2}{*}{ Factors } & \multicolumn{2}{|c|}{ Level of Knowledge } & \multicolumn{2}{|c|}{ Level of Attitude } \\
\hline & $\begin{array}{c}\text { Good } \\
\text { N }(\%) \\
(n=404)\end{array}$ & $\begin{array}{c}\text { Poor } \\
\text { N }(\%) \\
(n=112)\end{array}$ & $\begin{array}{c}\text { Positive } \\
\text { N }(\%) \\
(\mathbf{n}=142)\end{array}$ & $\begin{array}{c}\text { Negative } \\
\mathbf{N}(\%) \\
(\mathbf{n}=374)\end{array}$ \\
\hline \multicolumn{5}{|l|}{ Age group in years } \\
\hline - $\quad \leq 25$ years old & $204(50.5 \%)$ & $50(44.6 \%)$ & $58(40.8 \%)$ & $196(52.4 \%)$ \\
\hline - $\quad>25$ years old & $200(49.5 \%)$ & $62(55.4 \%)$ & $84(59.2 \%)$ & $178(47.6 \%)$ \\
\hline P-value & \multicolumn{2}{|c|}{0.273} & \multicolumn{2}{|c|}{$0.019 * *$} \\
\hline \multicolumn{5}{|l|}{ Gender } \\
\hline - Male & $173(42.8 \%)$ & $64(57.1 \%)$ & $64(45.1 \%)$ & $173(46.3 \%)$ \\
\hline - Female & $231(57.2 \%)$ & $48(42.9 \%)$ & $78(54.9 \%)$ & $201(53.7 \%)$ \\
\hline P-value & \multicolumn{2}{|c|}{$0.007 * *$} & \multicolumn{2}{|c|}{0.809} \\
\hline \multicolumn{5}{|l|}{ Marital Status } \\
\hline - $\quad$ Married & $161(39.9 \%)$ & $49(43.8 \%)$ & $72(50.7 \%)$ & $138(36.9 \%)$ \\
\hline - $\quad$ Non Married & $243(60.1 \%)$ & $63(56.2 \%)$ & $70(49.3 \%)$ & $236(63.1 \%)$ \\
\hline P-value & \multicolumn{2}{|c|}{0.457} & \multicolumn{2}{|c|}{$0.004 * *$} \\
\hline \multicolumn{5}{|l|}{ Educational level } \\
\hline - Secondary or below & $280(69.3 \%)$ & $81(72.3 \%)$ & $110(77.5 \%)$ & $251(67.1 \%)$ \\
\hline - Bachelor or above & $124(30.7 \%)$ & $31(27.7 \%)$ & $32(22.5 \%)$ & $123(32.9 \%)$ \\
\hline$P$-value & \multicolumn{2}{|c|}{0.538} & \multicolumn{2}{|c|}{$0.022 * *$} \\
\hline \multicolumn{5}{|l|}{ Classification of BMI } \\
\hline - Underweight & $27(06.7 \%)$ & $09(08.0 \%)$ & $03(02.1 \%)$ & $33(08.8 \%)$ \\
\hline - Normal & $164(40.6 \%)$ & $40(35.7 \%)$ & $48(33.8 \%)$ & $156(41.7 \%)$ \\
\hline - Overweight & $119(29.5 \%)$ & $31(27.7 \%)$ & $42(29.6 \%)$ & $108(28.9 \%)$ \\
\hline - Obese & $94(23.3 \%)$ & $32(28.6 \%)$ & $49(34.5 \%)$ & $77(20.6 \%)$ \\
\hline P-value & \multicolumn{2}{|c|}{0.601} & \multicolumn{2}{|c|}{$0.001 * *$} \\
\hline \multicolumn{5}{|l|}{ Knowledge of self-BMI } \\
\hline - $\quad Y e s$ & $36(08.9 \%)$ & $13(11.6 \%)$ & $24(16.9 \%)$ & $25(06.7 \%)$ \\
\hline - $\quad N o$ & $368(91.1 \% 0$ & $99(88.4 \%)$ & $118(83.1 \%)$ & $349(93.3 \%)$ \\
\hline P-value & \multicolumn{2}{|c|}{0.389} & \multicolumn{2}{|c|}{$<0.001 * *$} \\
\hline
\end{tabular}

\footnotetext{
*Significant results are typed in bold $(\mathrm{P}<0.05)$
} 


\section{REFERENCES}

[1] Ng M, Fleming T, Robinson M, Thomson B, Graetz N, Margono C, Mullany EC, Biryukov S, Abbafati C, Abera SF, Abraham JP. Global, regional, and national prevalence of overweight and obesity in children and adults during 1980-2013: a systematic analysis for the Global Burden of Disease Study 2013. The lancet. 2014 30;384(9945):766-81.

[2] Dallegri F, Carbone F. Epicardial adipose tissue and cardiovascular diseases. 2018.

[3] Beijers RJ, Huysmans S, van de Bool C, Kingma BR, Verdijk LB, van Loon LJ, Meex SJ, Gosker HR, Schols AM. MON-P145: The Effect of Dietary Nitrate Supplementation on Mechanical Efficiency and Cardiometabolic Risk Profile in Patients with Chronic Obstructive Pulmonary Disease. Clinical Nutrition. 2017 1;36:S232.

[4] NCD Risk Factor Collaboration. Worldwide trends in diabetes since 1980: a pooled analysis of 751 population-based studies with 4.4 million participants. The Lancet. 2016, 9;387(10027):1513-30.

[5] Johnston RA, Shore SA. Obesity and asthma: What have we learned from animal models?. InMechanisms and Manifestations of Obesity in Lung Disease 2019 Jan 1 (pp. 111-142). Academic Press.

[6] Spelta F, Pasini AF, Cazzoletti L, Ferrari M. Body weight and mortality in COPD: focus on the obesity paradox. Eating and Weight Disorders-Studies on Anorexia, Bulimia and Obesity. 2018, $1 ; 23(1): 15-22$.

[7] AM Iqbal, AR Dahl, A Lteif, S Kumar - Children, 2017 - mdpi.com

[8] Shapses SA, Pop LC, Wang Y. Obesity is a concern for bone health with aging. Nutrition Research. 2017, 1;39:1-3.

[9] World Atlas: 29 Most Obese Countries in the World. 2016. Retrieved from

http://www.worldatlas.com/articles/29-most-obese-countries-in-the-w orld.html

[10] Al-Nozha MM, Al-Mazrou YY, Al-Maatouq MA, Arafah MR, Khalil MZ, Khan NB, Al-Marzouki K, Abdullah MA, Al-Khadra AH, Al-Harthi SS, Al-Shahid MS. Obesity in Saudi Arabia. Saudi medical journal. 2005;26(5):824-9.

[11] Memish ZA, et al. "Burden of Disease, Injuries, and Risk Factors in the Kingdom of Saudi Arabia, 1990-2010". Prev Chronic Dis 2014;11:140176.

[12] Angrisani L, Santonicola A, Iovino P, Formisano G, Buchwald H, Scopinaro N. Bariatric surgery worldwide 2013. Obesity surgery. 2015 1;25(10):1822-32.

[13] Nguyen NT, Varela JE. Bariatric surgery for obesity and metabolic disorders: state of the art. Nature reviews Gastroenterology \& hepatology. 2017;14(3):160.

[14] Tuneu L, Ramos A, Genua I, Stantonyonge N, Caimari F, Balague C, Fernandez-Ananin S, Perez A, Minambres I. Effectiveness of bariatric surgery in metabolically healthy obese patients. In20th European Congress of Endocrinology 2018, 8 (Vol. 56). BioScientifica.

[15] Obesity: Preventing and Managing the Global Epidemic. Report of a WHO Consultation; World Health Organization: Geneva, Switzerland, 2000; Volume 894, pp. 1-253.

[16] Sarwer DB, Ritter S, Wadden TA, Spitzer JC, Marion L. Vetter ML, Moore RH. Attitudes About the Safety and Efficacy of Bariatric Surgery among Patients with Type 2 Diabetes and a Body Mass Index of $30-40 \mathrm{~kg} / \mathrm{m} 2$. Surg Obes Relat Dis. 2013 ; 9(5): doi:10.1016/j.soard.2012.10.007.

[17] Sikorski C, Luppa M, Dame K, Brähler E, Schütz T, Shang E, König $\mathrm{HH}$, Riedel-Heller SG. Attitudes towards bariatric surgery in the general public. Obesity surgery. 2013 1;23(3):338-45. 